\title{
Contribution of Biomotoric Components to the Performance Athletes Number Canoeing 1000 Meter
}

\author{
Syahid Nur Yasin ${ }^{1,2, *}$ \\ ${ }^{1}$ Prodi Pendidikan Olahraga, Sekolah Pascasarjana, \\ Universitas Pendidikan Indonesia \\ ${ }^{2}$ Pendidikan Jasmani Kesehatan dan Rekreasi, STKIP \\ Pasundan \\ Cimahi, Bandung, Indonesia \\ *syahid_bandung@yahoo.co.id
}

\author{
Amung Ma'mun, Agus Rusdiana \\ Prodi Pendidikan Olahraga, Sekolah Pascasarjana, \\ Universitas Pendidikan Indonesia \\ Bandung, Indonesia \\ amungmamun@upi.edu, agus.rusdiana@upi.edu
}

\begin{abstract}
The purpose of this study was to reveal a description of the contribution of biomotor components to the performance of paddle number 1000 meter canoeing athletes. The sample in this study were Indonesian male paddler national athletes totaling 19 people with an average age of 25 years, height 175 and weight 74. Components of the physical condition included muscle strength, upper body muscle endurance and general endurance. Using the method of data analysis techniques in this study using Factor Analysis. While the instrument used is a bench pull and bench press, a measuring instrument used to measure the endurance of chest muscles, back muscles and arm muscles. bench pull and bench press maximum strength, is a measuring instrument used to measure the level of chest muscle strength, back muscles and arm muscles. VO2Max (Run 12 minutes), $\mathbf{k m}$ is used to measure the level of cardiorespiratory endurance. The conclusions obtained from this study are: $\mathbf{8 2 . 1 \%}$ variation in 1000 meter Canoeing paddler performance can be explained by the variable VO2Max capacity and maximum strength capacity (strength pull). While the rest $(17.9 \%)$ are influenced by other causes
\end{abstract}

Keywords-canoeing; distance; muscle strength; muscle endurance; VO2Max

\section{INTRODUCTION}

Canoeing is an Olympic sport that is divided into two disciplines: canoe (C), where the athlete pedals on one side while kneeling on one knee, and like $(\mathrm{K})$, where the athlete paddles on both left and right sides in a sitting position. This is a sport where athletes compete to complete linear lines $(1,000 \mathrm{~m}, 500 \mathrm{~m}, 200 \mathrm{~m})$ in the fastest, non-flowing water [1]. The Olympic type Canoeing type consists of Kayak and Canoe and has been recognized by the international body namely ICF.

Each participant completed a distance test of $200 \mathrm{~m}, 500 \mathrm{~m}$ and $1000 \mathrm{~m}$ on a canoeing ergometer [2], with 24 hours of rest between each test. Each test is preceded by sufficient time to stretch and warm up and is accompanied by strong verbal encouragement. During the test, the subject receives visual reports of cumulative distance, speed, stroke rate, and elapsed time [3].
Paddle sports that the author researches are sports that are oriented towards achievement by analyzing several factors needed to achieve high achievement, muscle strength, muscle endurance, speed in increasing muscle tension in the body and legs [4].

This increase in lung capacity can contribute to increased maximum oxygen uptake (VO2max) [5]. Maximum oxygen uptake is defined as the highest oxygen volume that can be taken and used by a person's body for aerobic energy production. VO2Max can be expressed in absolute units (liters of oxygen per minute $[\mathrm{L} \times \min -1]$ ) or relative units (milliliters of oxygen per kilogram of body mass per minute $[\mathrm{ml} \times \mathrm{kg}-1 \times$ min-1]) [6]. VO2max is usually expressed in $\mathrm{ml} \times \mathrm{kg}-1 \times$ min1 because this value allows us to make comparisons between individuals and tells us who is most suitable for "pounds for pounds".

As has been explained that for high achievement, several components are needed. Here the author tries to connect several components with the results of the tests performed, including [7]:

\section{Bench Press, Bench Pull Strength Maximum Test [8]}

2. Bench Press, Bench Pull Maximum Endurance [9]

\section{VO2Max (Run 12 minutes) [6]}

And muscle strength and muscular endurance are also very important for this Canoeing type paddler sport, because it suits the character of the sport, because the rower is required to be able to row at a certain distance with maximum speed and can reach the finish line with the shortest time - in short.

Paddle sports are more oriented towards achievement targets by analyzing several factors needed to achieve high achievement. This is in line with the theory López-Plaza et al. as follows; Anthropometrics, Organic or functional, Mechanical; muscle strength, endurance, speed in increasing body and leg muscle tension, Psychological [10].

In paddler, an athlete must be able to maintain the stroke until it reaches the finish line, therefore another ability of a Canoeing type rower is general endurance, as explained by 
"Endurance is defined as the resistance of the organism to sustained high intensity work, or as the adaptation of the circulatory system to increation and sustained work or as the capacity of the athlete to resist fatigue. This is utilized when all oxygen is supplied by breathing during a sustained exercise" [11].

From the description above, the author takes an overview of each component of the physical condition of paddler sports so that there is suitability of interests and needs of the above. While this influence is not so clear that it attracts the writer to find out more.

\section{METHOD}

\section{A. Research Design}

Data analysis techniques in this study using Factor Analysis. This analysis tries to find the relationship between a number of variables that are mutually independent of one another so that one or more sets of variables can be made that are less than the number of initial variables. In this case the variables that have the greatest correlation will group together to form a variable set (forming a factor).

The next technique is by linear regression analysis with the backward elimination method. Backward method works by issuing one of the predictor variables that are not significant and are carried out continuously until there is no insignificant predictor variable.

\section{B. Participants}

The population in this study is a national Canoeing paddler athlete team on the concentration of national training to prepare for the 2018 Asian Games. Because of the limited ability of the author, it is impossible to conduct research on the population as a whole, for this purpose a sample is used. The sample used here is purposive as many as nineteen athletes $(n=19)$.

\section{Instrument}

The research instrument used in this study there are six forms of measuring instruments to obtain a number of data, namely: The research instrument used in this study there are several forms of measuring instruments to obtain a number of data, namely:

- Measurement of physical conditions, the instrument used is a tape measure, back number and whistle as well as a stopwatch to measure VO2Max, muscle endurance equipment used is a stop watch and load tool for Bench Pull and Bench Press, muscle strength of the tool used is a load tool for Bench Pull and Bench Press.

- Research location, Pelatnas Jatiluhur Purwakarta West Java.

\section{RESULTS AND DISCUSSION}

In the achievement variable of 1000 meters 0.446 , capacity of VO2Max 0.797 , quality of muscle endurance bench pulls 0.602 , muscle endurance quality of bench press 0.588 and muscle strength quality of bench pull 0.623 , quality of muscle strength bench press 0.573 . The MSA value of each variable is $>0.5$ then all variables can be processed further. 1000 meter paddler performance variable is 0.793 . This means that around $79.3 \%$ of the variance of the 1000 meter paddler performance variable can be explained by the factors formed. Variable VO2Max capacity is 0.354 , this means that $35.4 \%$ of the variants of the aerobic capacity variable can be explained by the factors formed. Likewise, for other variables. The smaller the value of communalities means the weaker the relationship with the factors that are formed.

In Total Variance Explained shows there are 6 factors formed from the 10 variables entered. Each eigenvalue factor> eigenvalue factor 1 is 2,409 with variance $(24.09 \%)$. The amount of variance that can be explained by the new factors formed is $24.09 \%$ while the remaining $75.91 \%$ is explained by other factors not examined.

The average canoeing performance of 1000 meters (with a total of 19 people) is 269.7158 with a standard deviation of 13.20207. The average VO2Max capacity (with a total of 19 people) is 58.2384 with a standard deviation of 3.82773. The average quality of muscle endurance bench pulls (with total data of 19 people) is 75.7895 with a standard deviation of 5.71138. The average quality of muscle endurance bench press (with total data of 19 people) was 82.8421 with a standard deviation of 14.43862 . The average quality of the bench pulls muscle strength (with a total of 19 people) is 119.5789 with a standard deviation of 6.70254 .

The average quality of the muscle strength of the bench press (with a total of 19 people) is 132.7895 with a standard deviation of 12.66921 . It must be noted that the number 0821 is only for two variables. The higher the adjusted R2 will be better for the regression model, because the independent variable can explain the greater dependent variable. This means that $82.1 \%$ of the 1000 meter Canoeing paddler performance variation can be explained by the variable endurance capacity and strength capacity. While the rest $(100 \%-82.1 \%=17.9 \%)$ is explained by other reasons.

It can be seen from the above model, there was an increase in Standard Error of Estimate, from 5.58230 on model 1, to 5.44942 on model 2. However, because it is smaller than the standard deviation of Canoeing paddler performance of 1000 meters (13.20207), the regression model is better in acted as a 1000 meter Canoeing paddler performance predictor rather than the average paddler performance itself.

Or it could be said, VO2Max capacity and strength pull capacity together affect the performance of a canoeing row of 1000 meters.

The level of significance of the one-sided correlation coefficient (measured by probability) yields varying numbers, with a note of strength press capacity variable, muscle endurance capacity in the form of endu pull and endu press is not significantly correlated (has a significance value above 0.05 ) with other variables. 
TABLE I. RESULTS

\begin{tabular}{|l|l|l|l|l|l|l|}
\hline Model & & Beta In & \multicolumn{1}{|c|}{$\begin{array}{c}\text { Partial } \\
\text { Correlation }\end{array}$} & $\begin{array}{c}\text { Collinearity } \\
\text { Statistics } \\
\text { Tolerance }\end{array}$ \\
\hline 2 & StrengthPress & $-.066^{\mathrm{b}}$ & -.584 & .569 & -.160 & .774 \\
\hline 3 & StrengthPress & $-.040^{\mathrm{c}}$ & -.384 & .707 & -.102 & .870 \\
& EnduPress & $.062^{\mathrm{c}}$ & .54 & .598 & .143 & .711 \\
\hline 4 & StrengthPress & $-.038^{\mathrm{d}}$ & -.37 & .719 & -.094 & .870 \\
& EnduPress & $.074^{\mathrm{d}}$ & .66 & .521 & .167 & .725 \\
& EnduPull & $-.097^{\mathrm{d}}$ & -.82 & .426 & -.207 & .649 \\
\hline & \multicolumn{5}{|c|}{ Pependent Variable: Seribumeter } \\
& \multicolumn{5}{|c|}{ Predictors in the Model: (Constant), VO2Max1, EnduPress, EnduPull, StrengthPull } \\
& \multicolumn{5}{|c|}{ Predictors in the Model: (Constant), VO2Max1, EnduPull, StrengthPull } \\
& \multicolumn{5}{|c|}{ Predictors in the Model: (Constant), VO2Max1, StrengthPull } \\
\hline
\end{tabular}

\section{CONCLUSION}

The relationship between the 1000-meter Canoeing paddler performance variable with the independent variable, sorted from largest to smallest, shows that the bench pulls muscle strength capacity and VO2Max capacity indicate a strong correlation. (the correlation between variables is above 0.5 )

The backward method starts by entering all variables. Then analysis and variables that are not feasible to enter the regression are issued one by one. Thus, after passing through 4 stages, the independent variables that are eligible to be included in the regression model are VO2Max Capacity and Strength Pull in the form of maximum pulling strength.

$82.1 \%$ of the variation in the 1000 meter Canoeing paddler performance can be explained by the variable VO2Max capacity and maximum strength capacity (strength pull). While the rest $(100 \%-82.1 \%=17.9 \%)$ is explained by other reasons.

The Sig / significance is 0,000 , or the probability is far below 0.05 , so Ho is rejected, or the regression coefficient is significant, or aerobic capacity (VO2Max) and maximum strength in the form of strength pull really significantly influence the performance of 1000 meter Canoeing paddler.

\section{REFERENCES}

[1] K. Suzukawa, Relationship between performance test and body composition / physical strength characteristic in sprint canoe and kayak paddlers, pp. 191-9, 2015
[2] L.P. Pripstein, E.C. Rhodes, D.C. McKenzie, and K.D.Coutts, "Aerobic and anaerobic energy during a $2-\mathrm{km}$ race simulation in female rowers". Eur J Appl Physiol Occup Physiol, vol. 79(6), pp. 491-4, 1999

[3] R.M. Sealey, K.F. Ness, and A.S. Leicht, Effect of self-selected and induced slow and fast paddling on stroke kinematics during $1000 \mathrm{~m}$ outrigger canoeing ergometry. June, pp. 52-8, 2011.

[4] (NSCA) NS and CA. Developing the core. pp. 215, 2013.

[5] M.C. Mccutcheon, S.A. Sticha, M.D. Giese, and F.J. Nagle, Research Quarterly for Exercise and Sport A Further Analysis of the 12-Minute Run Prediction of Maximal Aerobic Power. March, pp. 37-41, 2015.

[6] R.K. Tanner, A.I. of Sport, and C.J. Gore, Physiological Tests for Elite Athletes, pp. 560, 2012. [Online] Retrieved from: http://books.google.dk/books?id=ZEf1mgEACAAJ

[7] S.A. Ingham, G.P. Whyte, K. Jones, and A.M. Nevill, "Determinants of $2,000 \mathrm{~m}$ rowing ergometer performance in elite rowers". Eur J Appl Physiol, vol. 88(3), pp. 243-6, 2002.

[8] R. Vaquero-cristóbal, F. Alacid, and D. López-plaza, Kinematic Variables Evolution During a 200-m Maximum Test in Young Paddlers, vol. 38(September), pp. 15-22, 2013.

[9] J.K. Ward, P.A. Hastie, D.D. Wadsworth, S. Foote, S.J. Brock, and N. Hollett, "A Sport Education Fitness Season's Impact on Students' Fitness Levels, Knowledge, and In-Class Physical Activity". Res Q Exerc Sport, pp. 1-6. [Online] Retrieved from: https://www.tandfonline.com/doi/full/10.1080/02701367.2017.13211 $00,2017$.

[10] D. López-Plaza, F. Alacid, J.M. Muyor, and P.Á. López-Miñarro, "Sprint kayaking and canoeing performance prediction based on the relationship between maturity status, anthropometry and physical fitness in young elite paddlers". J Sports Sci, vol. 35(11), pp. 1083 90, 2017.

[11] S Boegman, and C.E. Dziedzic, "Nutrition and Supplements for Elite Open-Weight Rowing". Curr Sports Med Rep, vol. 15(4), pp. 252-61, 2016. 